\title{
Infrared radiation peeling experiment of yellow peach and optimization of technological parameters
}

\author{
Tianhang DING ${ }^{1}$,Weidong SONG ${ }^{1}$, Jiaoling WANG ${ }^{1}$, Jinji WU, Mingyou WANG ${ }^{1}$, Dehuan $\mathrm{ZHOU}^{1}$
}

\begin{abstract}
Conventional strong alkali spray peeling method for peeling yellow peach resulted in process hazard and negative environmental impacts. The efficacy of using infrared (IR) heating as an alternative method for peach peel removal was investigated to improve the operation safety and peeling quality. Herein, we introduce the Box-Behnken central combination method for conducting IR radiation tests. A multivariate regression model combining radiation distance, heating time and IR power as variable factors and surface temperature, full peeling time and firmness loss of yellow peach as the objective functions was developed to establish the optimal IR radiation parameters for peeling the skin of yellow peach. We found radiation distance of $76.18 \mathrm{~mm}$, heating time of $256.36 \mathrm{~s}$, and IR power was $1000 \mathrm{w}$ were the optimal conditions for this process. These conditions achieved surface temperature of $211.7^{\circ} \mathrm{C}$, firmness loss of $3.8 \times 10^{5} \mathrm{~Pa}$, and full peeling time of $149.6 \mathrm{~s}$. Thus, IR radiation is a feasible mechanism for peeling yellow peach, providing a new, safer and quality method for industrial processing of the fruit.
\end{abstract}

Keywords: infrared radiation; yellow peach; peeling; response surface methodology; optimization analysis.

Practical Application: Infrared peeling of yellow peach reduces operational hazards and pollution generation, improving quality of peeling, it has less influence on the shape and physical and chemical properties of pulp to achieve high-quality peeling effect, which provided further theoretical support for the infrared radiation peeling method of yellow peach.

\section{Introduction}

Yellow peaches are famous for their yellow and orange skin and pulp. They are rich in nutritional value and well accepted. In 2018, the total production of yellow peaches in China reached 554,000 tons, with a market value of 8.46 billion yuan (Hui, 2020). The bulk of yellow peaches are consumed as canned food. As such, peeling is a critical process for preparing canned yellow peaches. Presently, alkali leaching is the most widely used method for peeling fruits, but the complex and highly corrosive diffusion and chemical reactions combined with high working temperature may peel off part of the pulp fall, imparts bad test and results in the loss of nutrients (Pan et al., 2009; Li et al., 2014a; Wang et al., 2018). The chemical methods presents substantial occupational risks, consumes more energy and causes environmental pollution (Rock et al., 2012). This underlines the need for an efficient, safe and environmentally friendly method for peeling skin fruit skins.

In recent years, infrared (IR) technology has been studied as an alternative to food processing technology. It has the advantages of uniform heating, high heat transfer rate, short processing time, low energy consumption, high product quality and safety (Pan et al., 2011). There were many pieces of research on peeling tomatoes in the canned industry, a series of researches on the IR peeling of tomatoes was conducted, it was found that IR radiation intensity, heating time, emitter clearance and fruit size are the critical process parameters that affected the peeling performance (Krishnamurthy et al.,
2008; Li et al., 2014b), especially the IR radiation intensity and heating time (Wang \& Lin, 2009; Pan et al., 2015; Zhang \& Wang, 2013). The mechanism of lye peeling was different from that of IR heating. Radiation heating makes the epidermal cell layer collapse and reduces the epidermal adhesion. The feasibly of IR in peeling tomatoes has recently been reported (Li et al., 2014b; Pan et al., 2009). IR radiation utilizes thermal shock to loosen the skin, which then easily peels off. The advantage of IR is that the skin heats up quickly but the pulp remains cool (Xu et al., 2018; Vidyarthi et al., 2020). The peeling performance of IR method is comparable to that of conventional lye. However, losses from IR radiation are substantially low (Li, 2012; Li et al., 2009; Rene, 2016). The utility of IR method for peeling other vegetables has also been reported (Li et al., 2014c; Wang et al., 2016a; Vidyarthi et al., 2019a).

Previous studies showed that IR radiation heating contributes to peach peeling, and the principle was roughly equivalent to tomato IR peeling. Short-term heating by IR radiation could destroy the physical and chemical properties of the thin skin of the material, caused fruit and vegetable epidermal cells to collapse (Pan et al., 2009), and achieved the state of peel and pulp separation, but the effect was slightly worse than that of tomatoes. Manual peeling was used in previous studies to carry out the test, and there was a small amount of residual problem in the peel (Li et al., 2014c). Pre-experimental analysis revealed that the yellow peach heated by IR radiation was put into a low 
concentration of sodium carbonate solution for brushing peeling (this concentration solution had very poor peeling effect on the yellow peach without IR radiation and played an auxiliary role in IR peeling), it could completely peel the Yellow peach, eliminate the problem of peel residue and improve the production efficiency. Therefore, in order to improve the production efficiency of the products of yellow peaches, low concentration of sodium carbonate solution was used for subsequent auxiliary treatment in this experiment, which was beneficial to explore the parameter optimization of IR radiation peeling test of yellow peach.

Herein, we explored the feasibility of IR method in peeling yellow peaches, Anhui Dangshan Jinxiu variety. We aimed to provide a safe, efficient and environmentally friendly peeling method that yields quality fruit products. Optimal IR irradiation parameters for peeling yellow peach peeling were established.

\section{Materials and methods}

\subsection{Yellow peaches}

In this study, yellow peaches of Anhui Dangshan Jinxiu variety were sued for conducting peeling tests. To ensure the uniformity of materials, the yellow peaches were preliminary screened: the yellow peaches with skin abrasions and other defects were eliminated, and then the yellow peaches were screened according to the shape and size. In the known conclusion evidence, in studies with peaches size as a variable, the smaller the size, the more severe the peeling loss of peaches would be during IR heating (Li et al., 2014c). The measurement of the diameter of the same batch of yellow peaches showed that the yellow peaches with sizes between $60 \mathrm{~mm}$ and $70 \mathrm{~mm}$ accounted for $65 \%$ of the total. In order to unify the material size characteristics, the yellow peaches with small size differences were selected in this experiment, and peaches size was no longer studied as a variable. The selected peaches were placed in the refrigerator for refrigeration at $2 \pm 1{ }^{\circ} \mathrm{C}$, reducing the difference of fruits caused by the long-term test in the use process. The test needs to be completed within 2 days. At the same time, the peaches were placed in ambient temperature for 2 hours before the test so as to reach the ambient temperature state during the test.

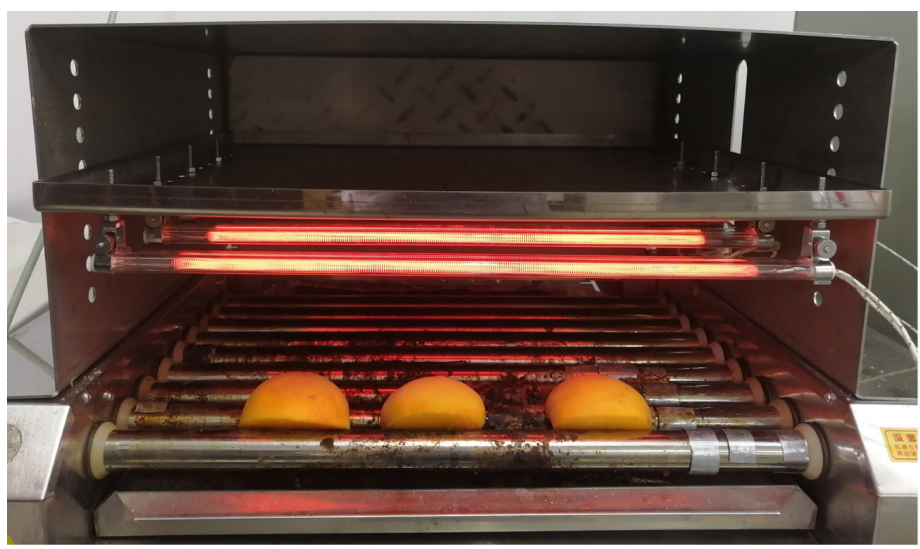

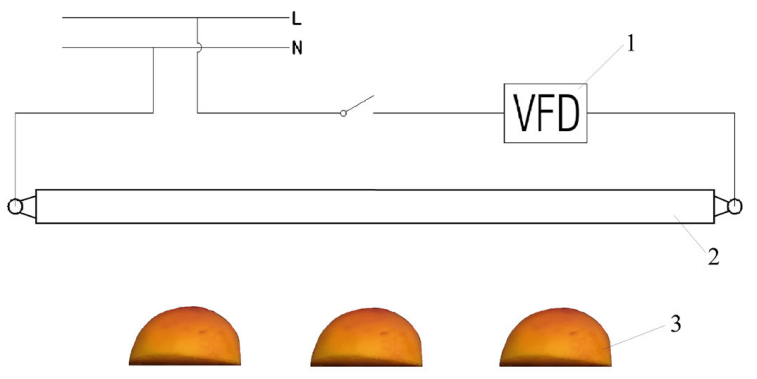

1. Variable-frequency drive 2. IR emitters 3. Yellow peaches

\subsection{IR radiation heating device}

IR radiation parameters such as IR power, radiation distance and other factors influence the efficiency of heating (Vidyarthi et al., 2019b). In the present study, the optimal parameters were reached through serial trials. IR radiation lamp was located at the top of the device (Figure 1). The IR emission device was purchased from Jiangsu Tianbao Ceramics Co., Ltd, and was equipped with a quartz material of 2.0-3.2 $\mu \mathrm{m}$ wavelength. The input power was adjustable. The irradiation conditions were adjusted to arrive at the most optimal conditions. The fruit was cut into four equal pieces and enucleated to mimic the characteristic of canned yellow peach. The pieces were placed between the bottom rollers and fixed in position before adjusting the height parameters. Preliminary screening of the test parameter range was carried out through preliminary experiments, and three-factor parameters were set, namely, radiation distance $(\mathrm{X} 1, \mathrm{~mm})$, heating time $(\mathrm{X} 2, \mathrm{~s})$ and IR power $(\mathrm{X} 3, \mathrm{~W})$, and each factor were set to three levels, the specific test factors and levels are shown in Table 1.

In this experiment, a relatively gentle peeling method was adopted. After being heated by IR radiation under various parameters, yellow peaches were put into sodium carbonate solution with a concentration of $8 \%$ at ambient temperature and completely soaked for a short time, and recording the time. Choose the brush with moderate hardness to brush the yellow peaches until the skin is fully peeling. Traditional strong lye exfoliation was to permeate and dissolve the skin by chemical diffusion (Wang et al., 2016b). The pre-experiment of peeling with different concentrations of sodium carbonate was carried out, and preliminary tests showed that $0.8 \mathrm{~mol} / \mathrm{kg}$ sodium carbonate solution would corrode the peaches that had not undergone

Table 1. Factors and levels of test.

\begin{tabular}{|c|c|c|c|}
\hline \multirow[b]{2}{*}{ Levels } & $X_{1}$ & $X_{2}$ & $X_{3}$ \\
\hline & $\begin{array}{l}\text { Radiation distance } \\
(\mathrm{mm})\end{array}$ & Heating time(s) & $\begin{array}{c}\text { Infrared } \\
\text { Power(W) }\end{array}$ \\
\hline-1 & 60 & 120 & 800 \\
\hline 0 & 80 & 240 & 900 \\
\hline 1 & 100 & 360 & 1000 \\
\hline
\end{tabular}

Figure 1. Picture of experimental setup for IR peeling of a yellow peach. 
IR radiation treatment was difficult to peel. However, peeling becomes easier after IR heating, which had a good auxiliary effect on IR heating peeling. This study mainly explored a safe and high-quality method of peeling yellow peach, the physiochemical reaction by IR radiation heating, and the process of efficient and high-quality peeling could also be completed under relatively soft conditions and complete the high-efficiency and high-quality peeling links. The hand-scrubbing method was implemented in the feasibility study to improve the peel removal capability (Li et al., 2014c), which could be replaced by a continuous mechanical device when the IR radiation peeling technology is fully developed in the future.

\subsection{Evaluation index}

Taking actual processing process of canned yellow peach into comprehensive consideration, combined with the characteristics of yellow peach peeling, in order to evaluate and analyze more reasonable quantitative indicators, the evaluation index of its peeling characteristics established in this paper were surface temperature $\left(Y_{1},{ }^{\circ} \mathrm{C}\right)$, firmness loss $\left(Y_{2}, \mathrm{~Pa}\right)$ and full peeling time $\left(Y_{3}, \mathrm{~s}\right)$.

\section{Surface temperature}

The principle of IR radiation peeling of yellow peach is similar to that of tomato thermal peeling. High temperature contributed to reduce the adhesion of pulp and peel, to change the physical and chemical properties of yellow peach skin. The surface temperature $\left(Y_{1},{ }^{\circ} \mathrm{C}\right)$ of yellow peach was the most direct observation value in IR radiation heating process and was an important indicator to reflect the IR radiation effect, especially essential to evaluating the peeling performance of yellow peach (Xu et al., 2014). IR thermometer (Fluke MT4 MAX type, Wuhan Yongsheng Technology Co., Ltd.) was used to measure the heated materials rapidly, three random points of the yellow peach epidermis were measured at the same time, and the average value was taken as the final result. The numerical value representting the quantity of heat after a specific period of time was used as the final temperature. Very low temperature does not improve the peeling efficiency, whereas very high temperature over-softens the fruit pulp, which peels off with the skin, resulting in substantial loss (Vidyarthi et al., 2019c, d). So appropriate surface temperature helped yellow peach reach the best peeling state and explore the optimal process parameters affecting the surface temperature, which was of reference significance for intuitive evaluation and prediction of peeling performance.

\section{Firmness loss}

The firmness of canned yellow peach was essential to the taste, the firmness of fresh yellow peach could be kept in the can, and the quality of canned yellow peach could be improved. In order to assess the firmness loss of canned yellow peach visually during heating, the difference between the firmness measured before and after heating was defined as firmness loss $\left(Y_{2}, \mathrm{~Pa}\right)$, the pointer fruit firmness meter (Aipu Instrument Co., Ltd.) was used to measure the firmness of yellow peach, reference fruit firmness standards determination method (China Agricultural Specialty Standard NY / T 2009-2011), repeat 3 times to take the average value. The specific measurement methods are as follows: Fruit firmness refers to the unit area of fruit under the pressure of a force spring, their ratio was defined as fruit firmness was calculated using Equation 1:

$p=F / S$

p-Firmness value of tested fruit, $\times 10^{5} \mathrm{~Pa}$

F-Stress on the tested fruit surface, $\mathrm{N}$

S- Stress area of tested fruit, $\mathrm{m}^{2}$

According to the firmness gradient distribution of 80 peaches selected randomly, the number of peaches with firmness between 7.5-8.5 $\times 10^{5} \mathrm{~Pa}$ accounted for $82 \%$ of the total number of peaches. The distribution diagram is shown in Figure 2. Peaches with too high or too low firmness were removed to reduce the individual differences of peaches and ensure the accuracy of the test. Yellow peaches of this value were taken as the final test fruit.

\section{Full peeling time}

In the processing of canned yellow peach, the requirement of peeling was very strict, and it must reach full peeled without any residue. Therefore, the conventional peeling rate in the evaluation index was no longer applicable because the peeling time was closely related to the production efficiency. Therefore, we aimed at establishing the most optimal peeling time $(Y, s)$, which is the irradiation time that ensures yellow peach is fully peeled without any residue sticking on the skin. Specifically, yellow peach heated using IR radiation was soaked in $0.8 \mathrm{~mol} /$ $\mathrm{kg}$ sodium carbonate solution before removing the skin through hand-scrubbing. Timing was started after soaking the fruit in sodium carbonate solution. The final value was an average of three experiments. The average value was obtained from the measurements under the same parameter condition three times as the final value.

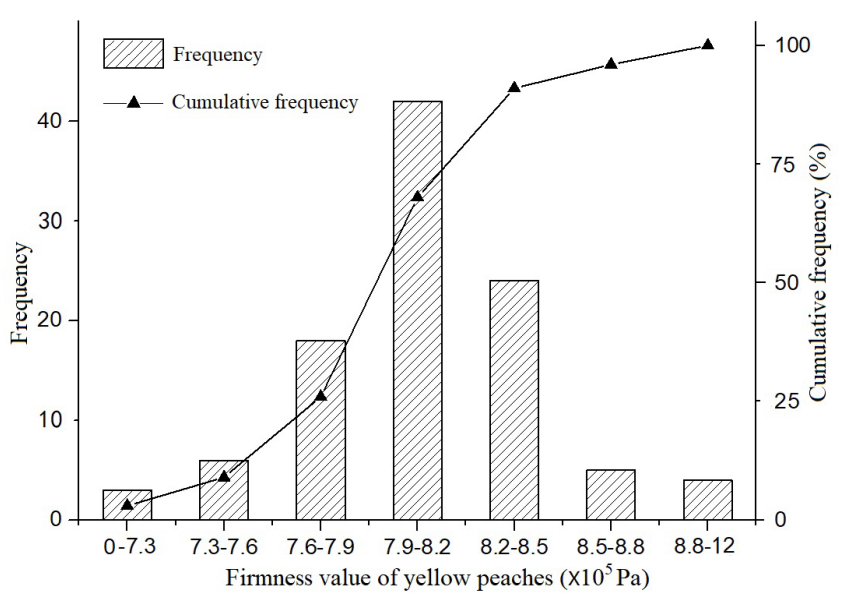

Figure 2. Accumulate frequency distributions of yellow peaches $(n=100)$. 


\subsection{Experimental design and statistical analysis}

Response Surface Methodology (RSM) is a statistical method that uses reasonable experimental design method and obtains certain data through experiments, uses multiple quadratic regression equations to fit the functional relationship between factors and response values, seeks the optimal process parameters through the analysis of regression equation, and solves the multivariate problem $(\mathrm{Xu} \& \mathrm{He}, 2010)$. The radiation distance $\left(X_{1}, \mathrm{~mm}\right)$, heating time $\left(X_{2}, \mathrm{~s}\right)$ and intensity $\left(X_{3}, \mathrm{~W}\right)$ were taken as independent variables, and each factor was set at three levels; the surface temperature $\left(Y_{1},{ }^{\circ} \mathrm{C}\right)$, firmness loss before and after radiation $\left(Y_{2}, \mathrm{~Pa}\right)$ and full peeling time $\left(Y_{3}, \mathrm{~s}\right)$ were taken as response variables, and three-factor and three-level quadratic regression orthogonal test scheme was designed. Seventeen groups of experiments were designed by Box-Behnken theory in RSM, scheme and response values are shown in Table 2, and the response values were analyzed to establish a peach peeling model. The experimental data were transformed into a secondorder polynomial model and the regression coefficients were calculated. The generalized quadratic equation for predicting the optimal point is explained as follows:

$Y=b_{0}+b_{1} X_{1}+b_{2} X_{2}+b_{3} X_{3}+b_{11} X_{1}^{2}+b_{22} X_{2}^{2}+b_{33} X_{3}^{2}+b_{12} X_{1} X_{2}+b_{13} X_{1} X_{3}+b_{23} X_{2} X_{3}(2)$

In Equation 2, the coefficients of polynomial terms are expressed by $b_{0}$ (constant term), $\mathrm{b}_{1}, b_{2}$ and $b_{3}$ (linear coefficient), $b_{11}, b_{22}$ and $b_{33}$ (quadratic term coefficient) and $b_{12}, b_{13}$ and $b_{23}$ (interaction term coefficient). Significant terms for each response in the model were found by analysis of variance (ANOVA), and significance was judged by the F value calculated from the data (Rene, 2016).

\subsection{Model validation}

RSM was used to optimize the response variables surface temperature $\left(Y_{1},{ }^{\circ} \mathrm{C}\right)$, firmness loss $\left(Y_{2}, \mathrm{~Pa}\right)$ and full peeling time
$\left(Y_{3}, \mathrm{~s}\right)$ before and after radiation, and the optimal boundary conditions were selected according to the actual production demand. The optimum peeling parameters (radiation spacing $X_{1}$, heating time $X_{2}$ and IR power $X_{3}$ ) were obtained, and the peeling effect was tested and verified. Finally, the model's predicted value was compared with the experimental value to measure whether the model was effective.

\section{Results and analysis}

\subsection{Data processing and analysis}

According to the principle of Box-Behnken test, the threefactor and three-level analysis test was designed. There were 17 test sites in the scheme, including 12 analysis factors and 5 zero point estimation errors. The test scheme and response values are shown in Table 2. The regression model was derived using the design-Expert software, V. 8.0.6, using data in Table 2 as previously described (Ge, 2015). The optimal radiation distance $\left(X_{1}\right)$, heating time $\left(X_{2}\right)$ and IR power $\left(X_{3}\right)$ for ideal surface temperature $\left(Y_{1}\right)$, firmness loss $\left(Y_{2}\right)$ and full peeling time $\left(Y_{3}\right)$ were established. The generated quadratic polynomial response surface regression model comprising three independent variables is shown in Equations 3 to Equation 5. The second-order polynomial models predicted by RSM showed a significant fitting $(\mathrm{p}<0.0001)$, and the lack of fit for all fitted models was found to be not significant ( $p>0.3907$ ), Non-significant lack of fit is good. The characteristic parameters of the results of variance analysis were selected to illustrate the model's reliability, as shown in Table 3.

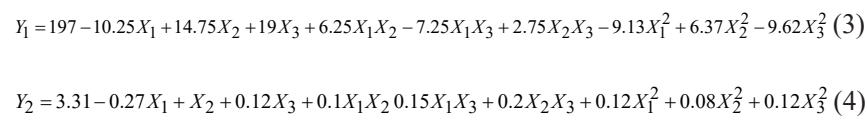

Table 2. Box-Behnken response surface design and response value.

\begin{tabular}{|c|c|c|c|c|c|c|}
\hline \multirow{3}{*}{ Order } & \multicolumn{3}{|c|}{ Factor } & \multicolumn{3}{|c|}{ Response } \\
\hline & $X_{1}$ & $X_{2}$ & $X_{3}$ & $Y_{1}$ & $Y_{2}$ & $Y_{3}$ \\
\hline & $\begin{array}{l}\text { Radiation distance } \\
(\mathrm{mm})\end{array}$ & Heating time(s) & Infrared Power(W) & $\begin{array}{c}\text { Surface } \\
\text { temperature }\left({ }^{\circ} \mathrm{C}\right)\end{array}$ & $\begin{array}{c}\text { Firmness } \\
\operatorname{loss}\left(\times 10^{5} \mathrm{~Pa}\right)\end{array}$ & $\begin{array}{l}\text { Full peeling time } \\
\text { (s) }\end{array}$ \\
\hline 1 & $60(-1)$ & $120(-1)$ & $900(0)$ & 196 & 2.6 & 314 \\
\hline 2 & $100(1)$ & $240(0)$ & $1000(1)$ & 180 & 3.2 & 264 \\
\hline 3 & 100 & $360(1)$ & 900 & 205 & 4.3 & 256 \\
\hline 4 & 60 & 240 & $800(-1)$ & 162 & 3.6 & 258 \\
\hline 5 & $80(0)$ & 240 & 900 & 198 & 3.2 & 195 \\
\hline 6 & 80 & 240 & 900 & 200 & 3.4 & 201 \\
\hline 7 & 60 & 360 & 900 & 213 & 4.5 & 204 \\
\hline 8 & 100 & 240 & 800 & 156 & 3.2 & 310 \\
\hline 9 & 60 & 240 & 1000 & 215 & 4.2 & 218 \\
\hline 10 & 80 & 120 & 800 & 163 & 2.5 & 270 \\
\hline 11 & 80 & 240 & 900 & 195 & 3.5 & 198 \\
\hline 12 & 80 & 360 & 800 & 187 & 4 & 125 \\
\hline 13 & 80 & 360 & 1000 & 230 & 4.6 & 120 \\
\hline 14 & 100 & 120 & 900 & 163 & 2 & 365 \\
\hline 15 & 80 & 240 & 900 & 190 & 3.2 & 206 \\
\hline 16 & 80 & 120 & 1000 & 195 & 2.3 & 192 \\
\hline 17 & 80 & 240 & 900 & 202 & 3.25 & 198 \\
\hline
\end{tabular}


$Y_{3}=199.6+25.13 X_{1}-54.5 X_{2}-21.13 X_{3}+0.25 X_{1} X_{2}-1.5 X_{1} X_{3}+18.25 X_{2} X_{3}+84.45 X_{1}^{2}-0.3 X_{2}^{2}-22.55 X_{3}^{2}(5)$

The surface temperature $\left(Y_{1},{ }^{\circ} \mathrm{C}\right)$, firmness loss $\left(Y_{2}, \mathrm{~Pa}\right)$ and full peeling time $\left(Y_{3}, \mathrm{~s}\right)$ were significant parameters influencing the peeling of yellow peach (all $\mathrm{P}<$ less than 0.0001 ). The $\mathrm{P}$-values for Lack of fit were $0.9989,0.3907$ and 0.9889 (all greater than 0.05), demonstrating the high goodness of fit of the regression equation. The R-Squared $\left(\mathrm{R}^{2}\right)$ for xyz were $0.9871,0.9847$ and 0.9872 , implying the three models explains more than $98 \%$ of the outcome, and the high overall fitting degree of the model. The standard deviation of xyz ranged between 0.14-3.56), demonstrating the accuracy of the model. Adjust R-Squared (Adj $\mathrm{R}^{2}$ ) was greater than 0.9651 . These values showed a good agreement between the experimental and the predicted values. The coefficient of variation (C.V. \%) was a statistic to measure the variation rate of each response value of the model. Generally, it was considered that the data with the coefficient of variation greater than $15 \%$ might be abnormal. In this paper, the c.v.\% is less than 4.21, indicating that the model has good stability. Adequate Precision represents the measurement of the signal to noise ratio and a ratio greater than 4 was desirable (Sui \& $\mathrm{Yu}, 2011)$. For the proposed models, Adequate Precision was between 27.135 and 98.181 , indicating a very good signal to noise ratio. Therefore, it can be assumed that the fitting model can optimize the radiation peeling performance of yellow peach.

The operating parameters for peeling performance were determined by the significant coefficients of the second-order

Table 3. Evaluation of response fitting quadratic model.

\begin{tabular}{cccc}
\hline \multirow{2}{*}{ Parameter } & \multicolumn{3}{c}{ Response variable } \\
\cline { 2 - 4 } & $\begin{array}{c}\text { Surface } \\
\text { temperature }\end{array}$ & Firmness loss & $\begin{array}{c}\text { Full peeling } \\
\text { time }\end{array}$ \\
\hline Model & $<0.0001^{*}$ & $<0.0001^{*}$ & $<0.0001^{*}$ \\
Lack of fit & $0.9989 \mathrm{~ns}$ & $0.3907 \mathrm{~ns}$ & $0.9609 \mathrm{~ns}$ \\
Std. Dev. & 3.56 & 0.14 & 3.25 \\
$\mathrm{R}^{2}$ & 0.9871 & 0.9847 & 0.9889 \\
Adj R & 0.9705 & 0.9651 & 0.9872 \\
c.v.\% & 1.86 & 4.21 & 1.42 \\
Adeq Precisior & 27.135 & 24.717 & 98.181 \\
\hline * Terms are significant $(\mathrm{p}<0.05) ;$ ns means that terms are not significant $(\mathrm{p}>0.05)$.
\end{tabular}

\footnotetext{
* Terms are significant $(\mathrm{p}<0.05)$; ns means that terms are not significant $(\mathrm{p}>0.05)$.
}

polynomial regression equation, which is shown in Table 4 along with respective p-values. P-value less than 0.05 indicates that the parameters had a significant impact on the model. After eliminating the insignificant regression terms in the model, the surface temperature $Y_{1}$, firmness loss $Y_{2}$ and full peeling time $\mathrm{Y}_{3}$ of the model were optimized. As shown in Equation 6 -Equation 8 , the $\mathrm{P}$ values of the three models were less than 0.0001 , and the $P$ values of Lack of fit were $0.8336,0.2064$ and 0.9823 , indicating that the three optimized models were reliable.

$$
\begin{aligned}
& Y_{1}=197-10.25 X_{1}+14.75 X_{2}+19 X_{3}+6.25 X_{1} X_{2}+2.75 X_{2} X_{3}-9.13 X_{1}^{2}+6.37 X_{2}^{2}-9.62 X_{3}^{2} \\
& Y_{2}=3.39-0.27 X_{1}+X_{2}+0.12 X_{3}+0.2 X_{2} X_{3} \\
& Y_{3}=199.6+25.13 X_{1}-54.5 X_{2}-21.13 X_{3}+18.25 X_{2} X_{3}+84.45 X_{1}^{2}-22.55 X_{3}^{2}
\end{aligned}
$$

In order to visually observe the effect of each parameter on the response index, the software Design Expert 8.0.6 was used to draw response surface graphs. The $3 \mathrm{D}$ response surface graphs were plotted to better visualize the significant interaction effects of operating parameters on the peel ability of peach. The optimal combination of peeling performance parameters was sought by analyzing the effect of interaction on each response and thenguiding the optimization of process parameters to achieve the best peeling effect.

\subsection{Effect of process parameters on peeling performance}

The operating parameters of peeling performance were determined by the effective coefficients of the second-order polynomial regression equation shown in Table 3 and the corresponding $\mathrm{P}$ values. The three-dimensional response surface maps of each factor on surface temperature $\left(Y_{1},{ }^{\circ} \mathrm{C}\right)$, firmness loss $\left(Y_{2}, \mathrm{~Pa}\right)$ and full peeling time $\left(Y_{3}, \mathrm{~s}\right)$ were drawn by using the software Design Expert 8.0.6 to visualize the interaction effects of each factor (Figures 3-5).

Previous studies on the surface temperature of yellow peach showed that the peeling performance of yellow peach was good under high temperature conditions (Li et al., 2014c). In order to better destroy the physical and chemical properties of the skin, the surface temperature of yellow peach should be increased

\begin{tabular}{|c|c|c|c|c|c|c|}
\hline \multirow{2}{*}{ Item } & \multicolumn{2}{|c|}{ Surface temperature } & \multicolumn{2}{|c|}{ Firmness loss } & \multicolumn{2}{|c|}{ Full peeling time } \\
\hline & Coefficient & Significant & Coefficient & Significant & Coefficient & Significant \\
\hline Constant & 197 & & 3.31 & & 199.6 & \\
\hline $\mathrm{X} 1$ & -10.25 & $<0.0001^{\star}$ & -0.27 & $<0.0009^{*}$ & 25.13 & $<0.0001^{\star}$ \\
\hline $\mathrm{X} 2$ & 14.75 & $<0.0001^{\star}$ & 1 & $<0.0001^{\star}$ & -54.5 & $<0.0001^{\star}$ \\
\hline $\mathrm{X} 3$ & 19 & $<0.0001^{\star}$ & 0.12 & $0.0421^{\star}$ & -21.13 & $<0.0001^{\star}$ \\
\hline $\mathrm{X}_{1} \mathrm{X}_{2}$ & 6.25 & $0.0098^{*}$ & 0.1 & 0.203 & 0.25 & 0.8821 \\
\hline $\mathrm{X}_{1} \mathrm{X}_{3}$ & -7.25 & $0.0047^{*}$ & -0.15 & 0.0732 & 1.5 & 0.3867 \\
\hline $\mathrm{X}_{2} \mathrm{X}_{3}$ & 2.75 & 0.1658 & 0.2 & $0.0232^{*}$ & 18.25 & $<0.0001^{\star}$ \\
\hline $\mathrm{X}_{1}^{2}$ & -9.13 & $0.0012^{*}$ & 0.12 & 0.1275 & 84.45 & $<0.0001^{\star}$ \\
\hline $\mathrm{X}_{2}^{2}$ & 6.37 & $0.0079^{*}$ & 0.08 & 0.2869 & -0.3 & 0.8552 \\
\hline $\mathrm{X}_{3}^{2}$ & -9.62 & $0.0009^{*}$ & 0.12 & 0.1275 & 22.55 & $<0.0001^{\star}$ \\
\hline
\end{tabular}
as much as possible to achieve the purpose of efficient peeling

Table 4. Estimated regression coefficient and its significance.

* Terms are significant $(\mathrm{p}<0.05)$ 

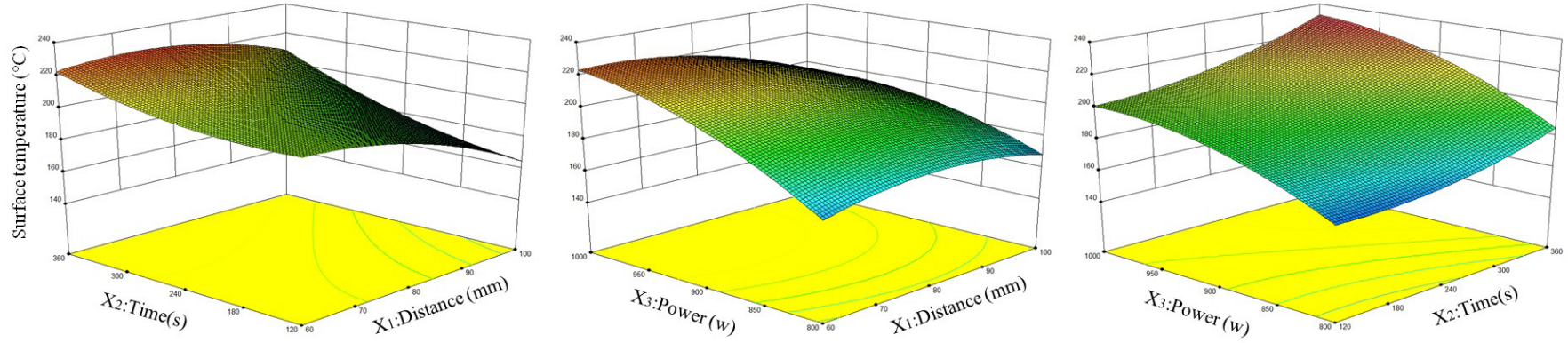

Figure 3. Effects of interactive factors on surface temperature.
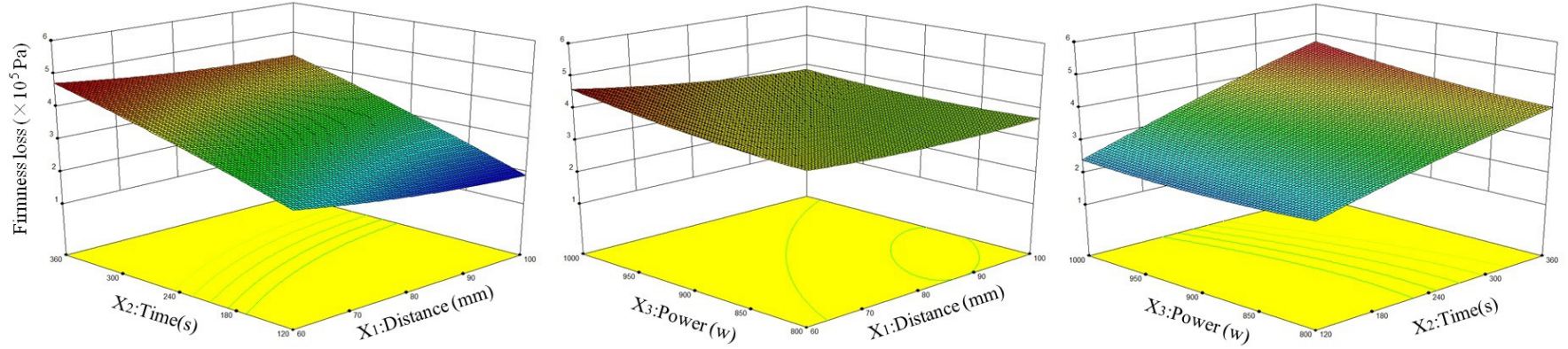

Figure 4. Effects of interactive factors on firmness loss.
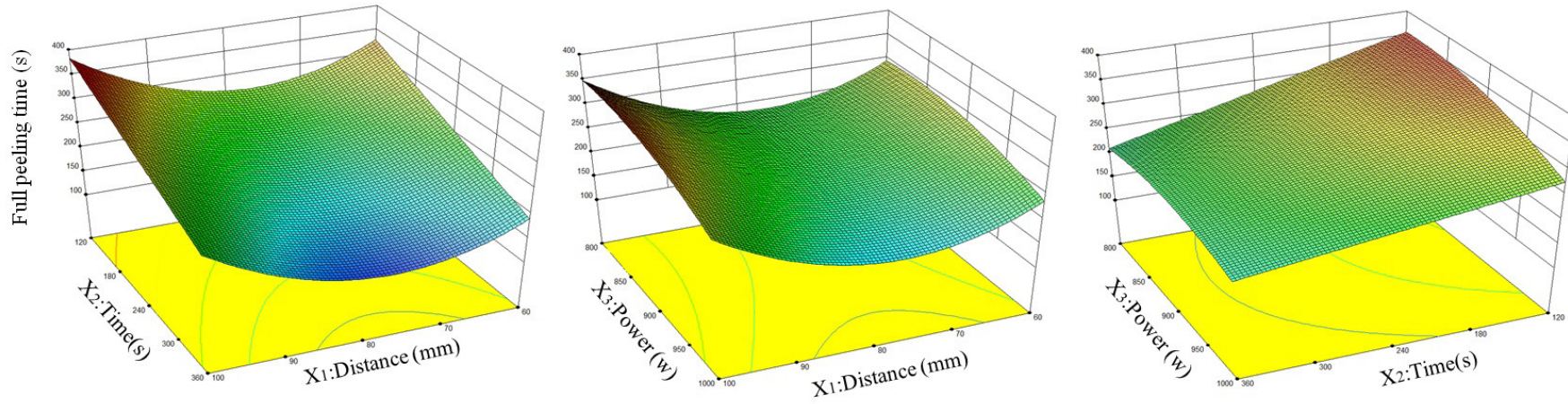

Figure 5. Effects of interactive factors on full pealing time.

under the condition of ensuring quality. As shown in Figure 3, the three-dimensional response surface analysis diagram of each factor on Y1 epidermal temperature shows that the test measured the surface temperature of the yellow peaches at $156-230{ }^{\circ} \mathrm{C}$, and the temperature range was comprehensively affected by three factors. It can be observed from Figure 3 that all factors had a significant impact on the temperature response. With the decrease of radiation distance, the surface temperature shows an increasing trend, in the high level of radiation power and heating time, the temperature rise of the yellow peach skin is more obvious; with the increase of heating time and IR power, the surface temperature of the yellow peach shows a rising trend. At the high level of IR power, the decrease of surface temperature with distance no longer shows an obvious trend of temperature rise, possibly because the temperature of the skin reached a certain limit, resulting in heat transfer from the shallow radiation to the pulp and then the increase of the surface temperature tended to slow down.

The degree of firmness of pulp had a very serious impact on the taste of canned fruit. After peeling, canned products can be made by processing, such as sugar blister. Too hard or too soft pulp can cause the quality of canned fruit to decline. Therefore, after peeling, the pulp of yellow peach achieved appropriate firmness, which greatly improved the quality of canned fruit. Firmness loss response refers to the firmness loss between the pre-heating and post-heating of the yellow peach, and its value was reflected 
Table 5. Predicted and experimental values of response under optimal conditions of independent variables.

\begin{tabular}{|c|c|c|c|c|c|c|c|c|}
\hline \multirow{2}{*}{ Factor } & \multicolumn{8}{|c|}{ Response } \\
\hline & \multicolumn{3}{|c|}{ Optimization results } & \multirow[b]{2}{*}{$\begin{array}{c}\text { firmness } \\
\operatorname{loss}\left(\times 10^{5} \mathrm{pa}\right)\end{array}$} & \multicolumn{2}{|c|}{ Test results } & \multirow[b]{2}{*}{$\begin{array}{c}\text { firmness } \\
\operatorname{loss}\left(\times 10^{5} \mathrm{pa}\right)\end{array}$} & \multirow[b]{2}{*}{$\begin{array}{l}\text { Full peeling } \\
\text { time(s) }\end{array}$} \\
\hline $\begin{array}{c}\text { Radiation } \\
\text { distance }(\mathrm{mm})\end{array}$ & $\begin{array}{l}\text { Heating } \\
\text { time(s) }\end{array}$ & $\begin{array}{c}\text { Infrared } \\
\text { Power(W) }\end{array}$ & $\begin{array}{c}\text { Surface } \\
\text { temperature } \\
\left({ }^{\circ} \mathrm{C}\right)\end{array}$ & & $\begin{array}{c}\text { Full peeling } \\
\text { time(s) }\end{array}$ & $\begin{array}{c}\text { Surface } \\
\text { temperature }\left({ }^{\circ} \mathrm{C}\right)\end{array}$ & & \\
\hline 76 & 256 & 1000 & 211.7 & 3.8 & 149.6 & 217 & 3.7 & 153 \\
\hline
\end{tabular}

in the effect of IR heat radiation on the firmness of the yellow peach pulp during the heating process. Maintaining appropriate firmness of the canned yellow peach could greatly improve the quality of the canned peaches. The firmness of each yellow peach before and after heating was measured and compared using a fruit firmness tester, and its value was recorded. According to the significant influence conditions of interaction, the response surface analysis diagram of firmness loss was drawn, as shown in Figure 4. It can be seen from Figure 4 that the IR power has less influence on the overall firmness loss and shows a slow upward trend. It may be due to the thin heating feature of IR radiation. IR energy was mainly absorbed by the skin, which increased the surface temperature of yellow peach. However, the firmness change of yellow peach was mainly caused by the change of its physical and chemical properties caused by heat transfer to the pulp. Increasing the IR power had no obvious effect on the heat transfer from the skin to the pulp, resulting in the phenomenon that the IR power had no obvious effect on the firmness loss. The effect of radiation distance factor and IR power on firmness loss was similar. The firmness loss of yellow peach increases slowly with the decrease of distance. Under the condition of low power level, the heat transferred from the skin to the pulp was less, and it was difficult for the pulp to reach a higher temperature under this condition. The firmness loss determined by temperature hardly changes with distance. Increasing heating time could transfer heat from the skin of the yellow peach to the pulp, and heat accumulates in the pulp, resulting in softening of the pulp. Figure 4 shows that the firmness loss of the yellow peach increases with the increase of heating time, and the increasing trend is very obvious. The main reason for this phenomenon was that the heat of the skin has sufficient time to transmit to the pulp. With the increase of time, the heat conduction accumulates in the pulp and then the temperature increased. The excessive temperature of the pulp causes changed in the internal physical and chemical properties, resulting in softening of the pulp and increased loss of firmness. In summary, firmness loss was closely related to the internal temperature of the yellow peach. Heat accumulates in the inner part of the yellow peach for a long heating time, and the formed high temperature softened the yellow peach and increased the firmness loss.

Full peeling time is the time required for the yellow peaches to reach the full peeling state in $0.8 \mathrm{~mol} / \mathrm{kg}$ sodium carbonate solution after IR heating. It mainly reflected the effect of various parameters on the physical and chemical properties of the yellow peach skin during the IR radiation process, which destroyed the tissue structure of the yellow peach skin so that it could corrode and peel in the weak alkali solution in a shorter time. Otherwise, the full peeling time increased. The three- dimensional time response surface of full peeling was plotted, as shown in Figure 5. The trend of heating time and IR power response to full peeling time was plotted too. It can be seen from Figure 5 that the time required for full peeling becomes shorter with the increase of heating time, and the relationship between them tends to be linear; with the increase of IR power, the time required for full peeling tended to be decreased, and the changing trend was relatively flat, which represented that the influence of IR power factor on the physical and chemical properties of yellow peach skin was weak. Compared with the other two factors, with the increase of radiation distance, the full peeling time showed a trend of first increasing and then decreasing, which indicated that the distance heated by IR radiation was not a simple linear relationship with the heating temperature, and there was the most suitable distance. In order to achieve a low level of full peeling time, we must find the best value of IR radiation distance. Only in the optimal distance conditions can the yellow peach skin achieve the ideal high temperature damage effect. The overall analysis found that the full peeling time was affected by three factors. The appropriate factor conditions could be the temperature of the yellow peach skin, which was conducive to destroying the adhesion of epidermal cells and reducing the full peeling of yellow peach. In industry, in order to improve work efficiency, the full peeling time was generally reduced as far as possible, and this response target was set as low as possible when optimizing the target.

Through comprehensive analysis, it was found that each response variable had three factors acting together, and heating time $\left(X_{2}, s\right)$ had a particularly significant effect on firmness loss $\left(Y_{2}, \mathrm{~Pa}\right)$ and full peeling time $\left(Y_{3}, \mathrm{~s}\right)$. Reaching a high level of surface temperature and full peeling time required an appropriate radiation distance but was not limited to this condition, and no response could be achieved in an ideal state by adjusting a single factor parameter. The factors corresponding to the optimal conditions of different response objectives were different. The comprehensive numerical optimization analysis of the three evaluation indicators was carried out to determine the specific optimal process parameters level to guide the practical production application.

\subsection{Parameter optimization and test verification}

\section{Parameter optimization}

Considering the impact of various factors on the test indexes varies, it is necessary to carry out multi-objective optimization to seek the best combination of factors to meet the IR heating peeling of yellow peach. The objective functions were designed according 
to the following requirements for the high surface temperature, low level of full peeling time and moderate firmness loss after radiation on the yellow peach: the surface temperature of yellow peach should be as high as possible, and the temperature range was: $126-230{ }^{\circ} \mathrm{C}$; the whole peeling time should be as short as possible, and the value range was $120-365 \mathrm{~s}$; As the firmness of the freshly picked Dangshan Jinxiu peaches is 7.5-8.5 $\times 10^{5} \mathrm{~Pa}$, factory production requires that the firmness loss value of yellow peach is $3.7-4.7 \times 10^{5} \mathrm{~Pa}$, so the target value of firmness loss was $3.8 \times 10^{5} \mathrm{~Pa}$. The optimal working parameters of each factor were obtained by using the design-Expert software. When the radiation distance was $76.18 \mathrm{~mm}$, the heating time was $256.36 \mathrm{~s}$, and the IR power was $1000 \mathrm{w}$, the predicted surface temperature of the yellow peach was $211.7^{\circ} \mathrm{C}$, the predicted firmness loss was $3.8 \times 10^{5} \mathrm{~Pa}$, and the predicted full peeling time was $149.6 \mathrm{~s}$.

\section{Test verification}

To verify the accuracy of the model prediction, the above parameters were used for three repeated tests on the IR test bench. Considering the operability of the test, the radiation distance was set to $76 \mathrm{~mm}$, the heating time was $256 \mathrm{~s}$, and the IR power was $1000 \mathrm{w}$. The results are shown in Table 5. According to the analysis of the results, the corresponding actual response values were as follows: the surface temperature was $217^{\circ} \mathrm{C}$, the firmness loss was $3.8 \times 105 \mathrm{~Pa}$, and the full peeling time was $153 \mathrm{~s}$. The experimental values of each performance index were in good agreement with the theoretical optimization values, and the relative errors of the experimental values were less than $5 \%$. Therefore, the parameter optimization model was reliable. The optimized combination used in the industrialized peeling processing of yellow peaches was as follows: the radiation distance was $76 \mathrm{~mm}$, the heating time was $256 \mathrm{~s}$, and the IR power was $1000 \mathrm{w}$.

To guarantee the uniformity of the heating of yellow peach surface, they were cut and placed in slices in the experiment. Although the accuracy of the radiation distance can be guaranteed, the problem of uniform radiation heating of the whole yellow peach still needs to be considered in the actual production. This test did not carry out a comprehensive test on factors such as hot alkali concentration, and subsequent tests can be carried out for comprehensive improvement of test bench or other factors. In actual industrial production, the parameter process is complex, so it is necessary to constantly improve the quality of test and research to guide the actual production and application better.

\section{Conclusion}

In general, we explored the conditions of IR thermal peeling of yellow peach for guiding the industrial application and pays attention to the working parameters of IR radiation peeling to carry out multi-factor analysis. A three-factor and three-level response surface test scheme was designed through Box-Behnken central combination test method and the peeling performance of canned yellow peach was studied under different parameters of IR radiation heating. Also, the working parameters under the optimal target condition of canned yellow peach peeling were explored and the results showed that under the conditions of radiation distance of $76.18 \mathrm{~mm}$, heating time of $256.36 \mathrm{~s}$ and
IR power of $1000 \mathrm{w}$, the response index of yellow peach was $211.7^{\circ} \mathrm{C}$, the firmness loss was $3.8 \times 10^{5} \mathrm{~Pa}$, and the complete peeling time was $149.6 \mathrm{~s}$, reaching the optimal solution. Then, a test was conducted with the optimized parameters and the result showed that the experimental values were close to the optimized predicted values and error was within 5\%, which indicates the reliability of the model prediction and is available to guide the practical production application. IR radiation heating can accelerate the radiation speed of the skin, while the heat accumulation of the skin transfers to the pulp to reduce the firmness of the yellow peach, which all meet the actual production needs of the factory well.

\section{Acknowledgements}

This research was supported by Fundamental Research Funds for Central Non-profit Scientific Institution (S20200601), and Agricultural Science and Technology Innovation Program of the Chinese Academy of Agricultural Sciences-Drying and Processing Equipment Team of Special Agricultural Products. Thanks for all your supports.

\section{References}

Ge, Y. (2015). Experimental design method and design expert software application. China: Harbin Institute of Technology Press.

Hui, N. (2020). China Yellow Peach Industry Development Report 2020. Retrieved from https://news.cnhnb.com/zixun/detail/422152/

Krishnamurthy, K., Jun, S., Irudayaraj, J., \& Demirci, A. L. I. (2008). Efficacy of infrared heat treatment for inactivation of staphylococcus aureus in milk. Journal of Food Process Engineering, 31(6), 798-816. http://dx.doi.org/10.1111/j.1745-4530.2007.00191.x.

Li, X. (2012). A study of infrared heating technology for tomato peeling: process characterization and modeling (Ph.D dissertation). Davis: University of California at Davis.

Li, X., Pan, Z., Bingol, G., McHugh, T. H., \& Atungulu, G. (2009). Feasibility study of using infrared radiation heating as a sustainable tomato peeling method. In Proceedings of the American Society of Agricultural and Biological Engineers International ASABE (Paper No. 095689). Reno, Nevada. St. Joseph, Michigan: ASABE.

Li, X., Pan, Z., Atungulu, G. G., Wood, D., \& McHugh, T. (2014a). Peeling mechanism of tomato under infrared heating: peel loosening and cracking. Journal of Food Engineering, 128(5), 79-87. http://dx.doi. org/10.1016/j.jfoodeng.2013.12.020.

Li, X., Pan, Z., Atungulu, G. G., Zheng, X., Wood, D., Delwiche, M., \& McHugh, T. (2014b). Peeling of tomatoes using novel infrared radiation heating technology. Innovative Food Science \& Emerging Technologies, 21(1), 123-130. http://dx.doi.org/10.1016/j.ifset.2013.10.011.

Li, X., Zhang, A., Atungulu, G. G., Delwiche, M., Milczarek, R., Wood, D., Williams, T., McHugh, T. H., \& Pan, Z. (2014c). Effects of infrared radiation heating on peeling performance and quality attributes of clingstone peaches. Lebensmittel-Wissenschaft + Technologie, 55(1), 34-42. http://dx.doi.org/10.1016/j.lwt.2013.08.020.

Pan, Z., Li, X., Bingol, G., McHugh, T. H., \& Atungulu, G. (2009). Development of infrared radiation heating method for sustainable tomato peeling. Applied Engineering in Agriculture, 25(6), 935-941. http://dx.doi.org/10.13031/2013.29227.

Pan, Z., Li, X., Yong, W., Atungulu, G., McHugh, T. H., \& Delwiche, M. (2011). Development of infrared heating technology for tomato peeling. In Proceedings of the the 11th International Congress on 
Engineering and Food (ICEF). Athens, Greece: Centre for Research and Technology Hellas.

Pan, Z., Li, X., Khir, R. E. I., Mashad, H. M., Atungulu, G. G., McHugh, T. H., \& Delwiche, M. (2015). A pilot scale electrical infrared drypeeling system for tomatoes: design and performance evaluation. Biosystems Engineering, 137(9), 1-8. http://dx.doi.org/10.1016/j. biosystemseng.2015.06.003.

Rene, R. F. (2016). Response Surface Methodology (RSM). In E. Drioli \& L. Giorno (Eds), Encyclopedia of membranes. Berlin: Springer. https://doi.org/10.1007/978-3-662-44324-8.

Rock, C., Yang, W., Goodrich-Schneider, R., \& Hao, F. (2012). Conventional and alternative methods for tomato peeling. Food Engineering Reviews, 4(1), 1-15.

Sui, Y., \& Yu, H. (2011). Improvement of response surface methodology and its application to engineering optimization. Pequim: Science Press.

Vidyarthi, S. K., El Mashad, H. M., Khir, R., Zhang, R., Tiwari, R., \& Pan, Z. (2019a). Quasi-static mechanical properties of tomato peels produced from catalytic infrared and lye peeling. Journal of Food Engineering, 254(8), 10-16. http://dx.doi.org/10.1016/j. jfoodeng.2019.03.001.

Vidyarthi, S. K., El Mashad, H. M., Khir, R., Upadhyaya, S. K., Singh, S. K., Zhang, R., Tiwari, R., \& Pan, Z. (2019b). A mathematical model of heat transfer during tomato peeling using selected electric infrared emitters. Biosystems Engineering, 86(10), 106-117. http:// dx.doi.org/10.1016/j.biosystemseng.2019.07.001.

Vidyarthi, S. K., El Mashad, H. M., Khir, R., Zhang, R., McHugh, T. H., \& Pan, Z. (2019c). Tomato peeling performance under pilot scale catalytic infrared heating. Journal of Food Engineering, 246(4), 224231. http://dx.doi.org/10.1016/j.jfoodeng.2018.11.002.

Vidyarthi, S. K., El Mashad, H. M., Khir, R., Zhang, R., Tiwari, R., \& Pan, Z. (2019d). Evaluation of selected electric infrared emitters for tomato peeling. Biosystems Engineering, 184(8), 90-100. http:// dx.doi.org/10.1016/j.biosystemseng.2019.06.006.
Vidyarthi, S.K., EI Mashad, H.M., Khir, R., Zhang, R., Tiwari, R., \& Pan, Z. (2020). Viscoelastic properties of tomato peels produced from catalytic infrared and lye peeling methods. Food and Bioproducts Processing, 119(1).337-344.

Wang, B., Venkitasamy, C., Zhang, F., Zhao, L., Khir, R., \& Pan, Z. (2016a). Feasibility of jujube peeling using novel infrared radiation heating technology. Lebensmittel-Wissenschaft + Technologie, 69, 458-467. http://dx.doi.org/10.1016/j.lwt.2016.01.077.

Wang, W., Ma, X., Jiang, P., Hu, L., Zhi, Z., Chen, J., Ding, T., Ye, X., \& Liu, D. (2016b). Characterization of pectin from grapefruit peel: a comparison of ultrasound-assisted and conventional heating extractions. Food Hydrocolloids, 61(6), 730-739. http://dx.doi. org/10.1016/j.foodhyd.2016.06.019.

Wang, W., Wang, L., Feng, Y., Pu, Y., Ding, T., Ye, X., \& Liu, D. (2018). Ultrasound-assisted lye peeling of peach and comparison with conventional methods. Innovative Food Science \& Emerging Technologies, 47(6), 204-213. http://dx.doi.org/10.1016/j.ifset.2018.02.016.

Wang, X., \& Lin, X. (2009). Influence factors of kinetics of infrared radiation drying for fruits and vegetables. Nongye Jixie Xuebao, 40(10), 114-120.

Xu, B., Zhou, T., Wei, B., Ren, X., \& Ma, H. (2018). Catalytic infrared radiation improving peeling effect and quality of cherry tomatoes. Nongye Gongcheng Xuebao (Beijing), 34(24), 299-305.

$\mathrm{Xu}, \mathrm{X} ., \mathrm{\&} \mathrm{He}, \mathrm{M}$. (2010). Experimental design and design expert, SPSS application. Beijing: Science Press.

Xu, Y., Zhang, L., Bailina, Y., Ge, Z., Ding, T., Ye, X., \& Liu, D. (2014). Effects of ultrasound and/or heating on the extraction of pectin from grapefruit peel. Journal of Food Engineering, 126, 72-81. http:// dx.doi.org/10.1016/j.jfoodeng.2013.11.004.

Zhang, L., \& Wang, X. (2013). The thin-layer drying characteristics of garlic slices under infrared radiation. Food Science and Technology (Campinas), 38(11), 94-97. 